\title{
Paper
}

\section{Nickel Free PM Steels}

\author{
Bruce Lindsley, W. Brian James, Tony Nishida and Kalathur S. Narasimhan \\ Hoeganaes Corporation, 1001 Taylers Lane Cinnaminson, NJ 08077, USA.
}

Received June 21, 2011

\begin{abstract}
SYNOPSIS
There is a growing need in the PM industry for materials with reduced or no $\mathrm{Cu}$ or $\mathrm{Ni}$ and also lesser total alloying elements to minimize costs. Towards this end, a variety of research activities have been undertaken and this manuscript is a report on $\mathrm{Cu}$-free and Nickel-free steels that have been developed. The combination of $\mathrm{Mn}$ with a moderate level of Mo results in PM steel alloys with mechanical properties approaching and/or surpassing those of the diffusion alloy FD-0405. Equally important, these alloys can be processed under typical, industrial sintering conditions. With accelerated cooling, these manganese steels can be used as lean alloy, sinter-hardening grades. The benefits of ferrous PM alloys containing manganese are discussed.
\end{abstract}

KEY WORDS

Manganese steel, Ni-free, Cu-free, Sinter hardening, Ancorbond FLM

\section{Introduction}

Manganese is a relatively low cost alloying element used extensively in wrought steels and improves both the mechanical properties and hardenability, thohgh not extensively used in PM industry. The limitations are due to processing conditions required for the $\mathrm{Mn}$ containing PM steels. Alloying manganese in water atomized PM steel using high carbon ferro-alloys of manganese (and chromium) has been successfully used as sources for $\mathrm{Mn}$ (and $\mathrm{Cr}$ ) in PM steels ${ }^{1-4)}$, but these additives require high temperatures and long sintering times to be effective. Medium carbon ferro-manganese was utilized by Dudrova et $\mathrm{al}^{5)}$ to develop alloys with promising properties when sintered in semi-closed containers at $1180^{\circ} \mathrm{C}$. Zhang et $\mathrm{al}^{6)}$ studied various $\mathrm{Fe}-\mathrm{Mn}$-Si master alloys added to a $0.85 \% \mathrm{Mo}-\mathrm{Fe}$ prealloy and obtained a range of properties with changes in composition and sintering temperature. More recently, a Fe-Mn-C additive was developed based on thermodynamical criteria that allowed sintering at conventional sintering temperatures ${ }^{7}$. In all cases, $\mathrm{Mn}$ diffuses away from the additive into the iron by both gas and solid state diffusion. Gas phase diffusion quickly distributes Mn throughout the pore network in the compact, strengthening sintered necks between particles and resulting in rapid mechanical property development with conventional sintering times. Successful studies have shown that a hydrogen or hydrogen-nitrogen sintering atmosphere is required with $\mathrm{Mn}$-alloyed steels.

The current study builds on earlier research ${ }^{8)}$ that showed $\mathrm{Mn}$ steels can be produced and sintered using conventional practices. A proprietary additive is used as the $\mathrm{Mn}$ source and when added to Mo-based steels, shows promising results. The combination of Mo and Mn provides good hardenability, thereby boosting as-sintered hardness and yield strength. This paper discusses the properties of Mn steels and compares them with traditional PM alloys, including several diffusion-alloyed materials.

\section{Experimental Procedure}

The nominal composition of the Mn alloys is given in Table 1 . Alloy 1 and 2 are commercially available grades ANCORBOND FLM-4005 and FLM-4405, respectively. The manganese alloys were compared with the diffusion alloys FD-0205, FD-0405 and FLD-49DH in premixes containing $0.6 \%$ graphite and $0.75 \%$ EBS wax. TRS, 'dog bone' tensile and impact specimens were compacted at pressures from 415 to $690 \mathrm{MPa}$.

The laboratory specimens were sintered in a belt furnace for 15 minutes at temperature ( 45 minutes in the hot zone) of $1120^{\circ} \mathrm{C}$ in an atmosphere of $90 \mathrm{~N}_{2}-10 \mathrm{H}_{2}$ (vol.\%). Two average cooling rates, measured between 650 and $315^{\circ} \mathrm{C}$, were obtained during the study: $0.7^{\circ} \mathrm{C} / \mathrm{s}$, and $1.6^{\circ} \mathrm{C} / \mathrm{s}$. A 
Table 1 Nominal composition of the base alloys studied.

\begin{tabular}{|c|c|c|c|c|c|}
\hline ID & $\begin{array}{c}\mathrm{Fe} \\
\text { (wt. \%) }\end{array}$ & $\begin{array}{c}\text { Mo } \\
\text { (wt. \%) }\end{array}$ & $\begin{array}{c}\mathrm{Ni} \\
\text { (wt. \%) }\end{array}$ & $\begin{array}{c}\mathrm{Cu} \\
\text { (wt. \%) }\end{array}$ & $\begin{array}{c}M n \\
\text { (wt. \%) }\end{array}$ \\
\hline $\begin{array}{c}\text { Alloy } 1 \\
\text { (FLM-4005) }\end{array}$ & Bal. & $0.5^{\star}$ & - & - & 1.3 \\
\hline $\begin{array}{c}\text { Alloy } 2 \\
\text { (FLM-4405) }\end{array}$ & Bal. & $0.8^{*}$ & - & - & 1.3 \\
\hline FD-0205 & Bal. & $0.5^{\star \star}$ & $1.8^{* *}$ & $1.5^{* *}$ & $0.1^{*}$ \\
\hline FD-0405 & Bal. & $0.5^{\star *}$ & $4^{* *}$ & $1.5^{* *}$ & $0.1^{*}$ \\
\hline FLD-49DH $^{\dagger}$ & Bal. & $1.5^{*}$ & - & $2.0^{* *}$ & $0.1^{*}$ \\
\hline
\end{tabular}

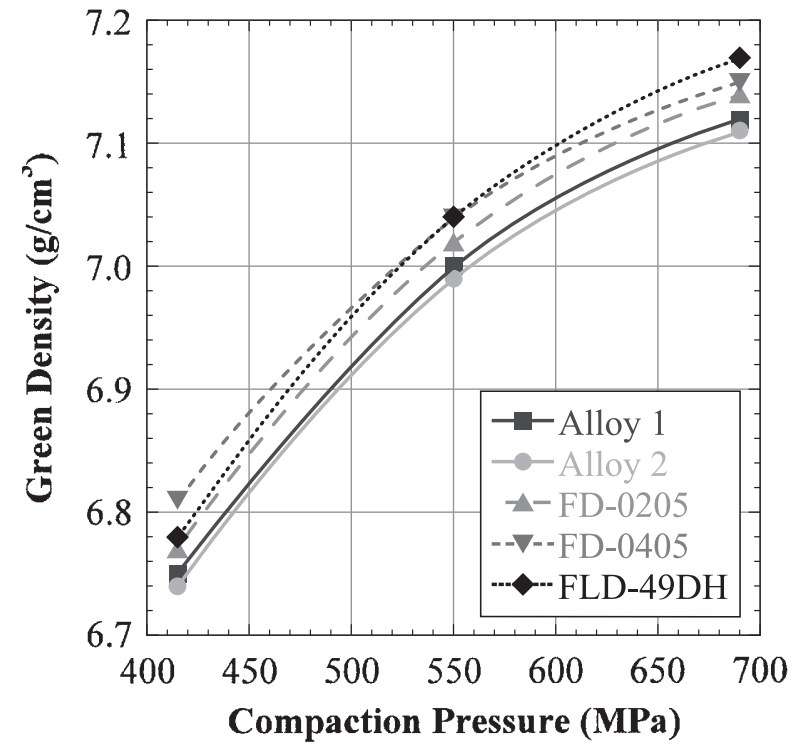

Fig.1 Compressibility of alloys studied.

tempering temperature of $205^{\circ} \mathrm{C}$ for 1 hour was used for samples with accelerated cooling. Dimensional change was measured from die size. Tensile yield strength was measured at $0.2 \%$ offset (plastic strain).

Jominy end-quench hardenability specimens were prepared using the technique described in reference 9.100 $\mathrm{mm}$ by $25 \mathrm{~mm}$ diameter bars at nominally $7.0 \mathrm{~g} / \mathrm{cm}^{3}$ were end quenched from $900^{\circ} \mathrm{C}$. An additional test was run at $950^{\circ} \mathrm{C}$ for alloy FLD-49DH, as it was found that the hardenability of higher molybdenum alloys is underreported with lower austenitizing temperatures ${ }^{9}$. The hardenability of alloys FD-0205 and FD-0405 are derived from MPIF standard 35 data and estimated for a density of $7.0 \mathrm{~g} / \mathrm{cm}^{3}$.

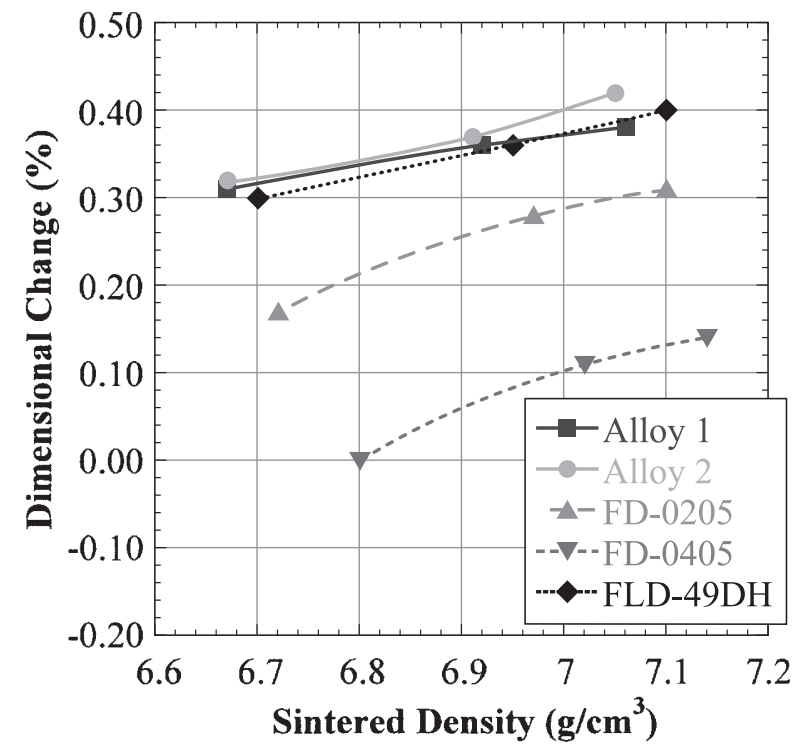

Fig.2 Dimensional change of the 5 alloys.

\section{Results}

3.1 Compressibility and Dimensional Change

The diffusion-alloyed materials, FD-0205, FD-0405 and FLD-49DH, were chosen as comparison materials with the $\mathrm{Mn}$ steels. The compressibility of the Mn steels is $\leq 0.06$ $\mathrm{g} / \mathrm{cm}^{3}$ lower than the three highly compressible diffusion alloys over a range of compaction pressures (Fig. 1). Upon sintering at $1120^{\circ} \mathrm{C}$, the Ni-containing alloys shrink relative to the other alloys (Fig. 2). The dimensional change of the $\mathrm{Mn}$ steels is similar to the Ni-free diffusion alloy FLD49DH. Manganese additions were found to cause growth similar to that of $\mathrm{Cu}$ additions.

\subsection{Microstructure}

The microstructures of the Mn-containing alloys are 
presented in Fig. 3 and Fig. 4. The morphology consists of martensitic and bainitic regions for both alloys. The martensitic regions etch tan-colored, whereas the bainitic regions are white and gray. The amount of martensite clearly increases with faster cooling rates and with increased molybdenum content. Not only does the amount of martensite increase with the increase in Mo content, but the ferrite-carbide spacing in the upper bainite/divorced pearlite decreases and the amount of lower bainite increases. As with most hybrid-alloy systems, the martensite content is highest in the vicinity of the pore network, thereby strengthening the connections between prior iron particles. The microstructure of FLD-49DH is similar to that of the Mn steels, and contains bainitic and martensitic regions, Fig. 5. The diffusion-alloyed FD-0205 and FD-0405 materials exhibit microstructures containing ferrite/pearlite, bainite, martensite and alloy-rich, non- etching martensite/retained austenite.

3.3 Mechanical Properties

Table 2 contains the mechanical property data for the five alloys studied. The values in the table are interpolated from the plots of sintered density versus physical property at a density of $7.0 \mathrm{~g} / \mathrm{cm}^{3}$. As seen in the table and in Fig. 6 , the apparent hardness of the manganese-containing alloys rivals that of the high alloy sinter-hardening FLD-49DH at both conventional and accelerated cooling. The ironbased diffusion alloys FD-0205 and FD-0405 have considerably lower hardness, especially with faster cooling rates. Yield strength follows a similar trend (Fig. 7). The yield strength of FLD-49DH falls between the $0.5 \%$ Mo and $0.8 \%$ Mo plus $\mathrm{Mn}$ alloys at both cooling rates. The yield strength of both Mn-containing steels is far superior to FD-0205 and FD-0405. This is due in part to the pure iron base used to produce FD alloys, that results in lower
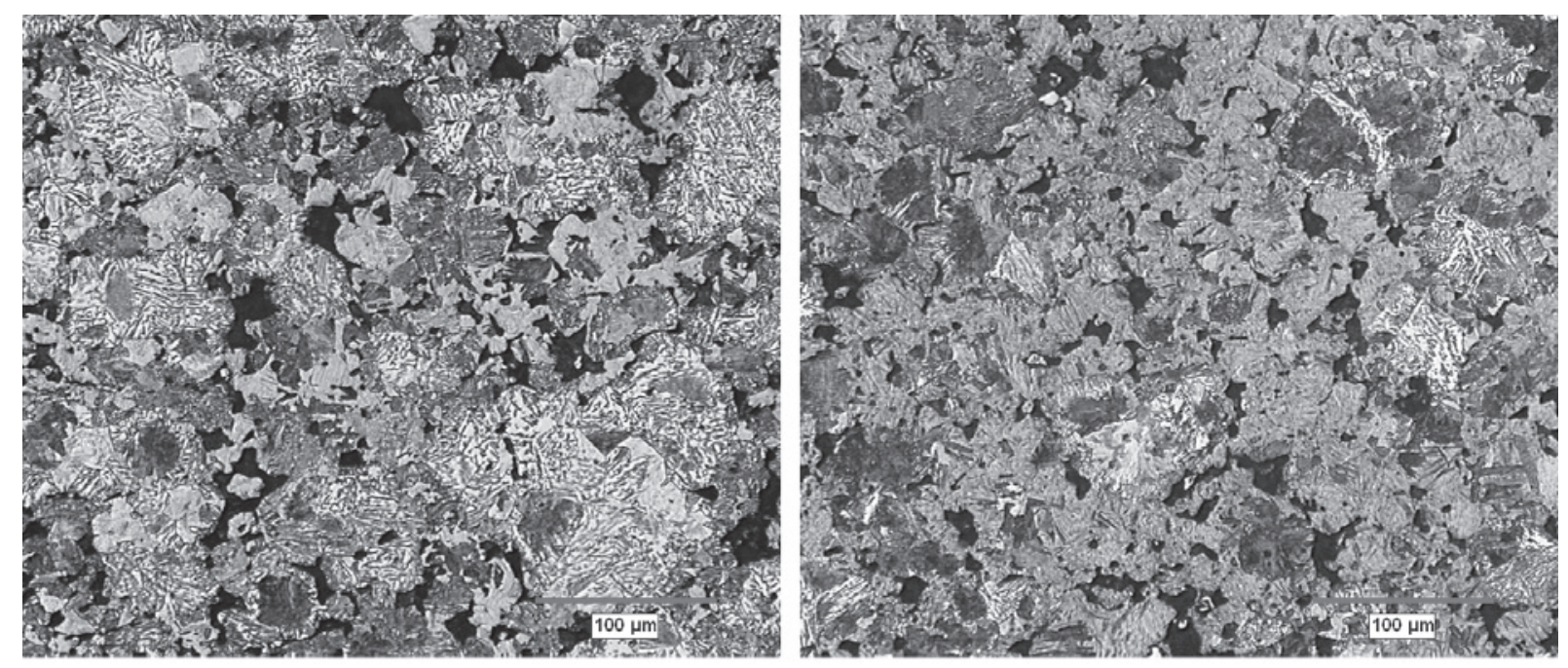

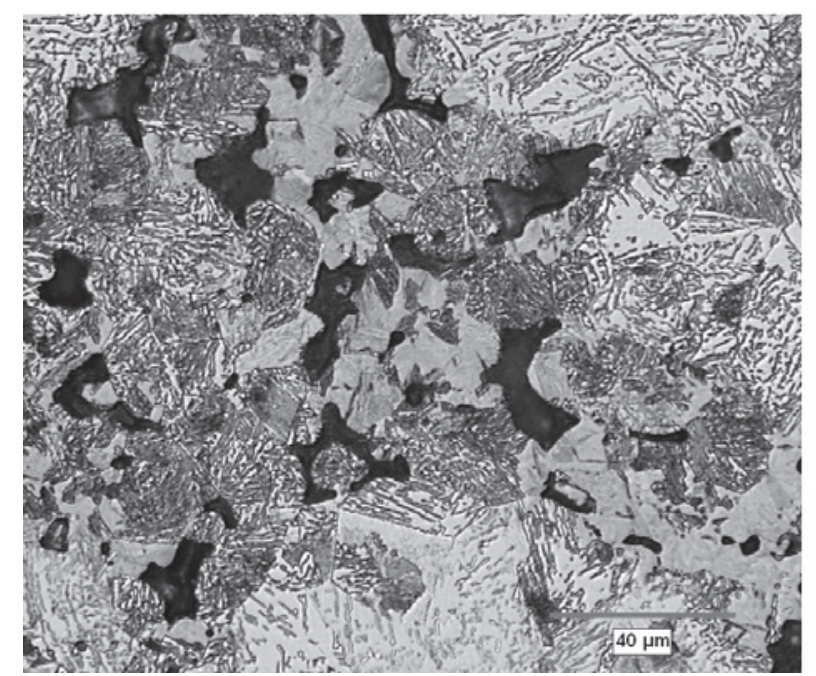

a

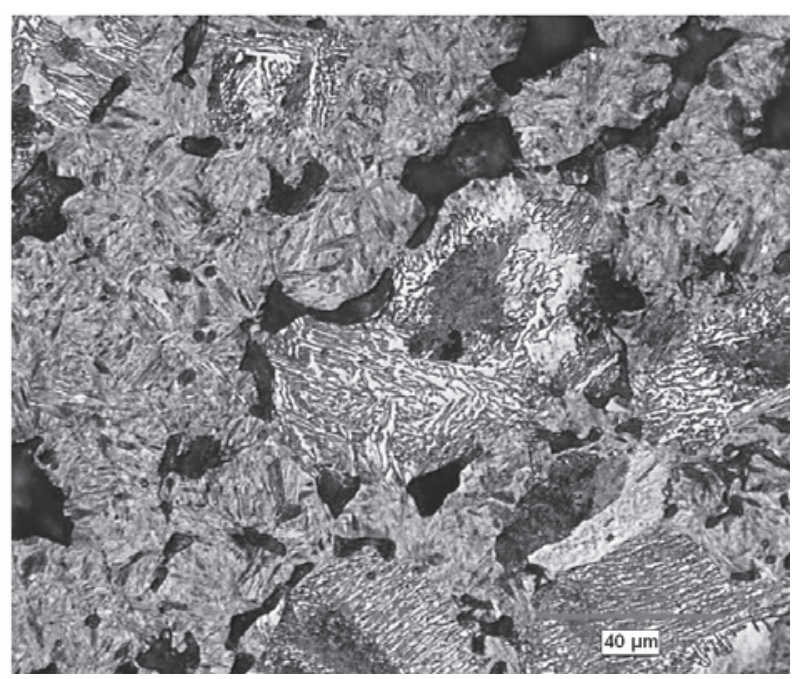

b

Fig.3 Microstructure of Alloy $1(1.3 \% \mathrm{Mn}, 0.5 \% \mathrm{Mo}, 0.6 \%$ graphite) cooled at (a) conventional and (b) accelerated cooling rates. Samples were etched with $2 \%$ nital $-4 \%$ picral. 

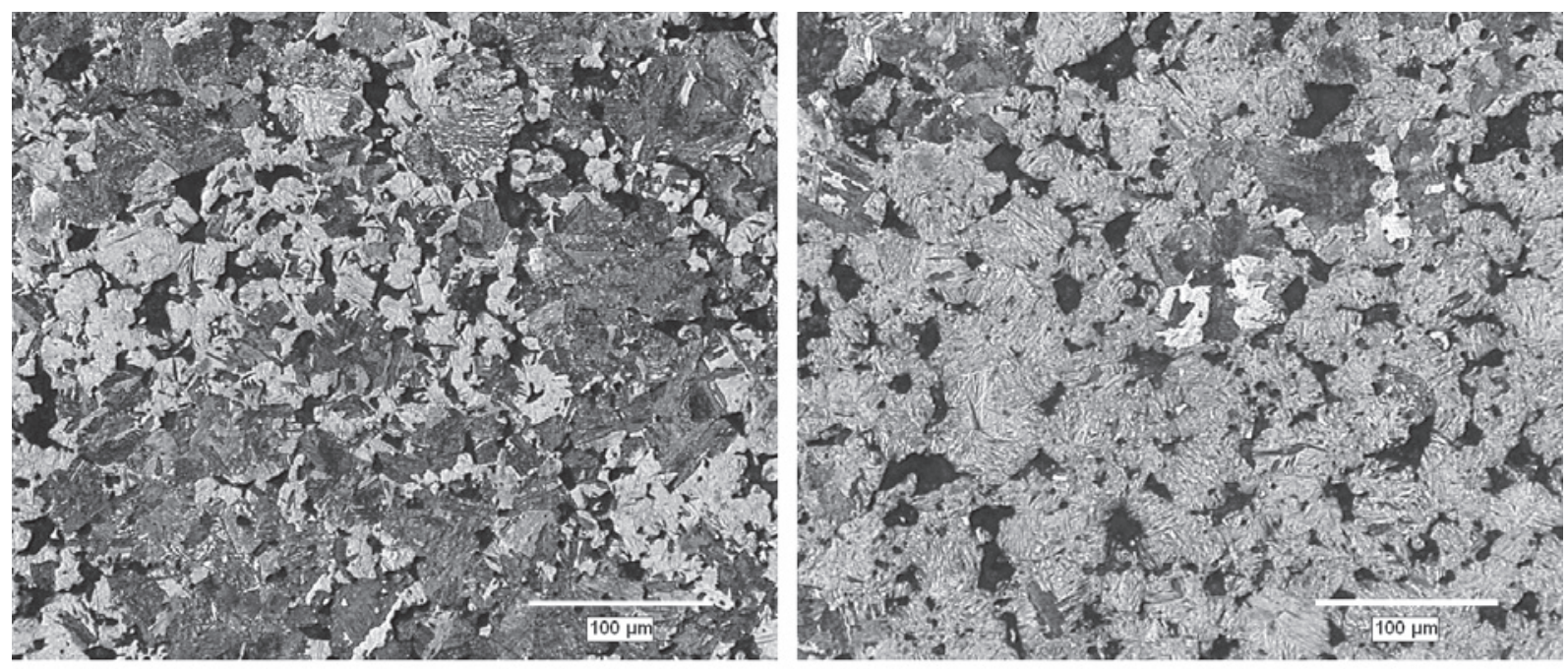

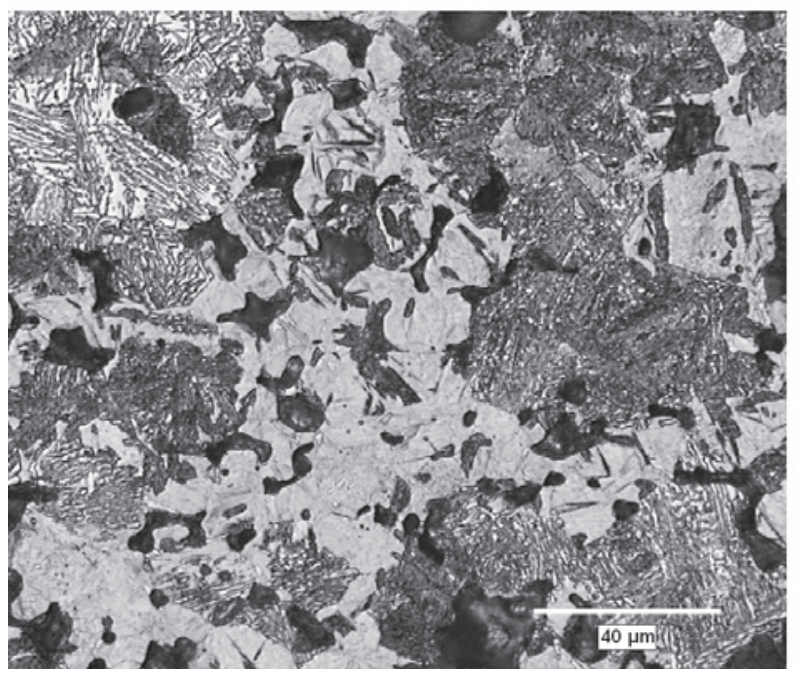

a

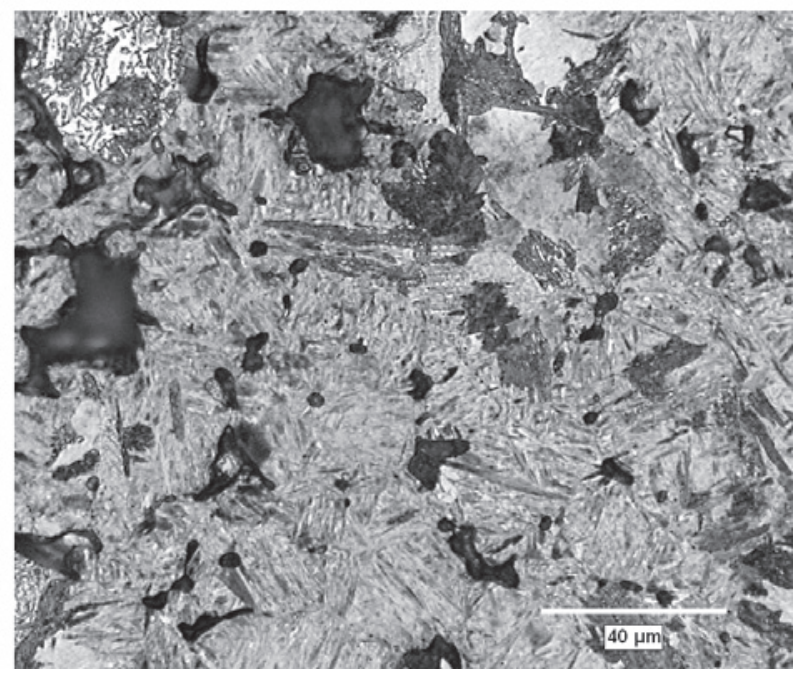

b

Fig.4 Microstructure of Alloy $2(1.3 \% \mathrm{Mn}, 0.8 \% \mathrm{Mo}, 0.6 \%$ graphite) cooled at (a) conventional and (b) accelerated cooling rates. Samples were etched with $2 \%$ nital $-4 \%$ picral.

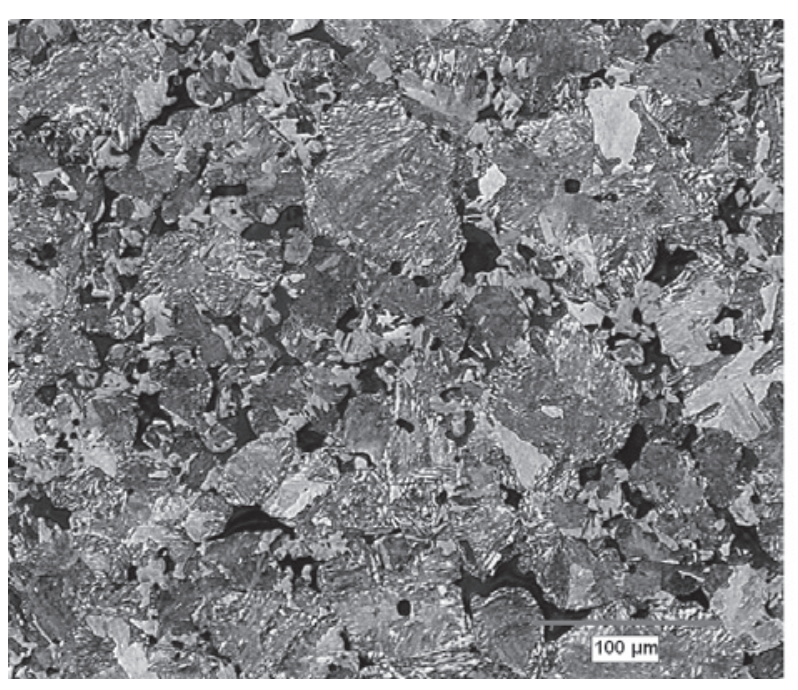

a

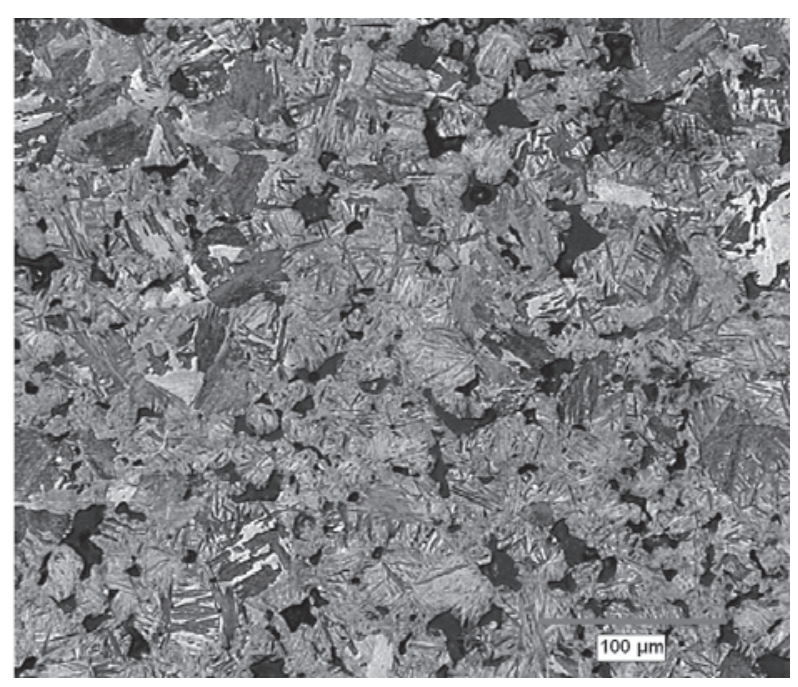

b

Fig. 5 Microstructure of FLD-49DH (1.5\% Mo, $2 \% \mathrm{Cu}, 0.6 \%$ graphite) cooled at (a) conventional and (b) accelerated cooling rates. Samples were etched with $2 \%$ nital $-4 \%$ picral. 
Table 2 Mechanical property data for a $7.0 \mathrm{~g} / \mathrm{cm}^{3}$ sintered density (interpolated).

\begin{tabular}{|c|c|c|c|c|c|c|c|}
\hline Base Alloy & $\begin{array}{c}\text { Cooling } \\
\text { Rate }\left({ }^{\circ} \mathrm{C} / \mathrm{s}\right)\end{array}$ & $\begin{array}{c}\mathrm{DC} \\
(\%)\end{array}$ & $\begin{array}{c}\text { Hardness } \\
(\mathrm{HRA})\end{array}$ & $\begin{array}{c}0.2 \% \text { YS } \\
(\mathrm{MPa})\end{array}$ & $\begin{array}{c}\text { UTS } \\
(\mathrm{MPa})\end{array}$ & $\begin{array}{c}\text { Elong. } \\
(\%)\end{array}$ & $\begin{array}{c}\text { Impact } \\
(\mathrm{J})\end{array}$ \\
\hline Alloy 1 & 0.7 & +0.36 & 58 & 485 & 640 & 1 & 12 \\
\hline Alloy 2 & 0.7 & +0.40 & 64 & 570 & 675 & 1 & 11 \\
\hline FD-0205 & 0.7 & +0.29 & 53 & 390 & 600 & 2 & 21 \\
\hline FD-0405 & 0.7 & +0.10 & 57 & 400 & 670 & 2 & 24 \\
\hline FLD-49DH & 0.7 & +0.36 & 57 & 530 & 670 & 1 & 13 \\
\hline & & & & & & & \\
\hline Alloy 1 & 1.6 & +0.38 & 64 & 650 & 765 & 1 & 13 \\
\hline Alloy 2 & 1.6 & +0.42 & 68 & 780 & 845 & 1 & 12 \\
\hline FD-0205 & 1.6 & +0.30 & 55 & 440 & 660 & 2 & 22 \\
\hline FD-0405 & 1.6 & +0.07 & 57 & 460 & 730 & 2 & 23 \\
\hline FLD-49DH & 1.6 & +0.44 & 66 & 750 & 785 & $<1$ & 13 \\
\hline
\end{tabular}

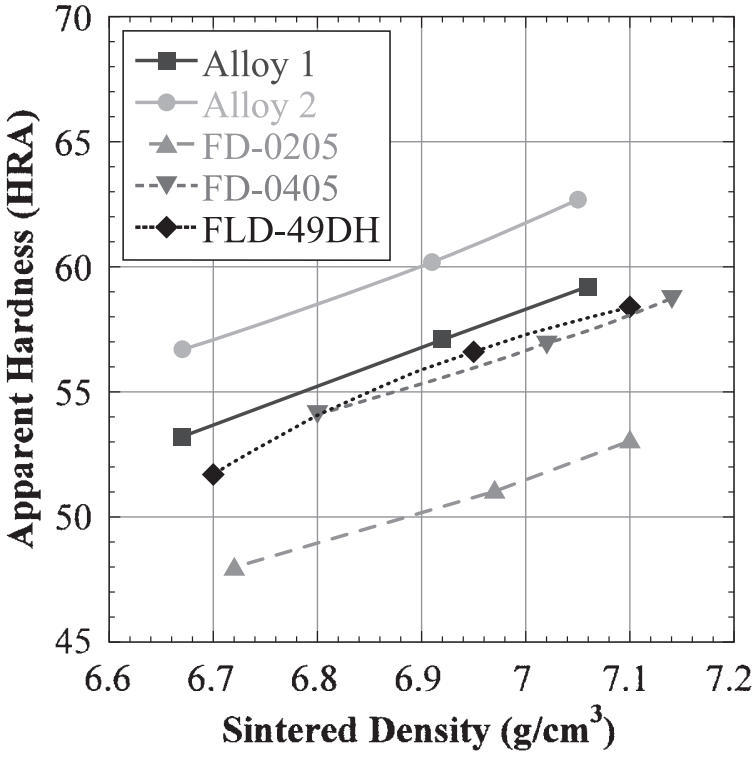

a

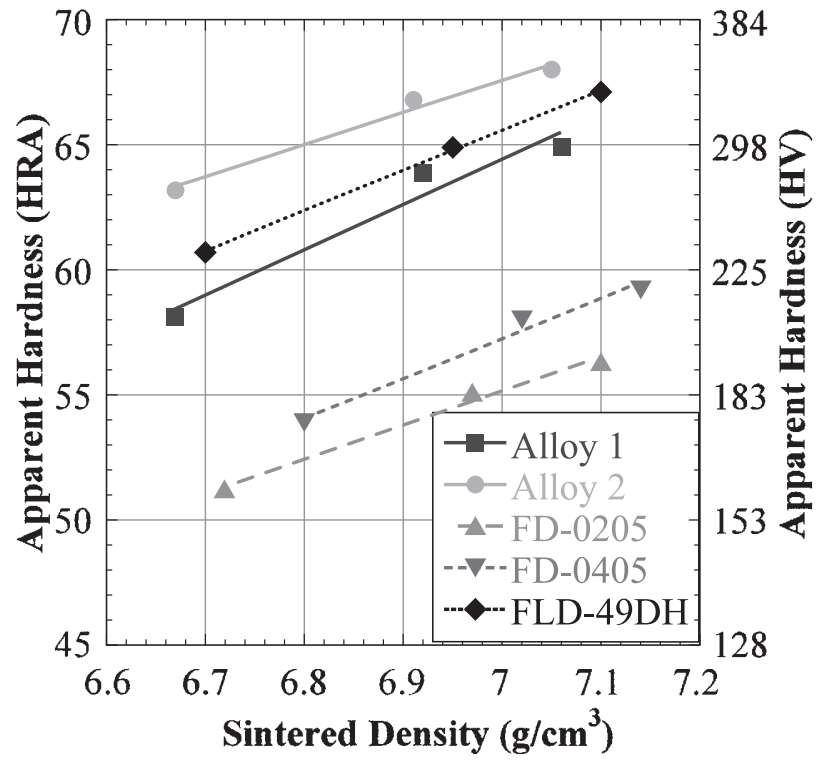

b

Fig.6 Apparent hardness of the 5 alloys (a) with conventional cooling $\left(0.7^{\circ} \mathrm{C} / \mathrm{s}\right)$ and (b) with accelerated cooling $\left(1.6^{\circ} \mathrm{C} / \mathrm{s}\right)$ plus tempering. Vickers hardness is estimated using ASTM E140 Table 1.

alloy, lower strength regions in the microstructure. The ultimate tensile strength (UTS) of the manganese alloys is equivalent to that of FD-0405 and FLD-49DH at conventional cooling rates. The higher Mo Alloy 2 exhibits the highest UTS with accelerated cooling. The ductility and impact properties of the $\mathrm{Mn}$ alloys are similar to that of the $\mathrm{Ni}$-free diffusion alloy FLD-49DH, whereas the $\mathrm{Ni}$ -containing FD-0205 and FD-0405 have much higher values. Nickel is known to improve toughness in PM steel, so these results are not surprising. Additionally, the Mncontaining alloys sintered with conventional cooling could be tempered to improve the mechanical properties as martensite is present in the microstructure.

\subsection{Hardenability}

The hardenability of PM alloys utilizing prealloyed Mo is greatly improved compared with those where the Mo is introduced via diffusion alloying ${ }^{10}$. Jominy end-quench tests were performed to quantify the hardenability of the Mn-Mo alloys. Figure 8 shows the results, where a greater distance from the quenched end ( $\mathrm{J}$ depth) indicates greater hardenability. The iron-based diffusion alloys have poor hardenability, as evidenced by the short distances and the low apparent hardness and yield strengths in Figures 6 and 7. Alloy 1 exhibits better hardenability than the more highly alloyed FD-0405, with a J depth of $16 \mathrm{~mm}$. FLD49DH has greater hardenability than Alloy 1, but it was 


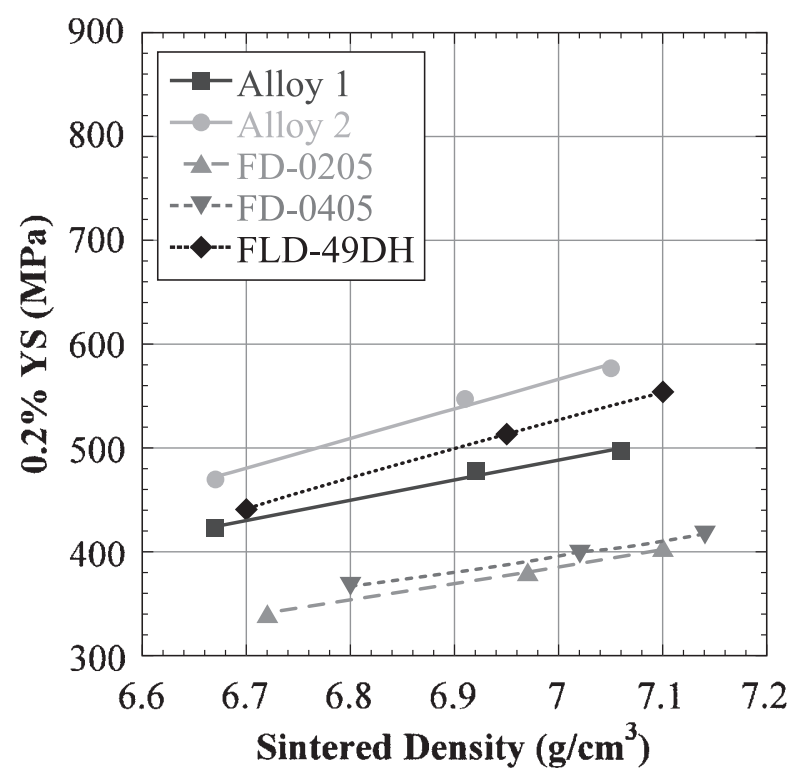

a

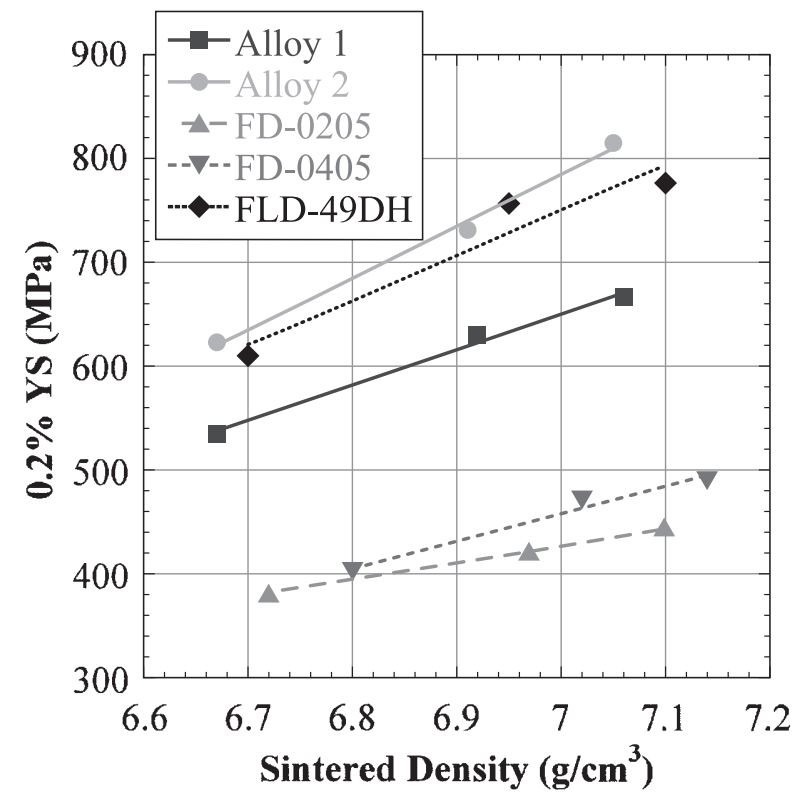

b

Fig.7 Yield strength of the 5 alloys (a) with conventional cooling $\left(0.7^{\circ} \mathrm{C} / \mathrm{s}\right)$ and (b) with accelerated cooling $\left(1.6^{\circ} \mathrm{C} / \mathrm{s}\right)$ plus tempering.

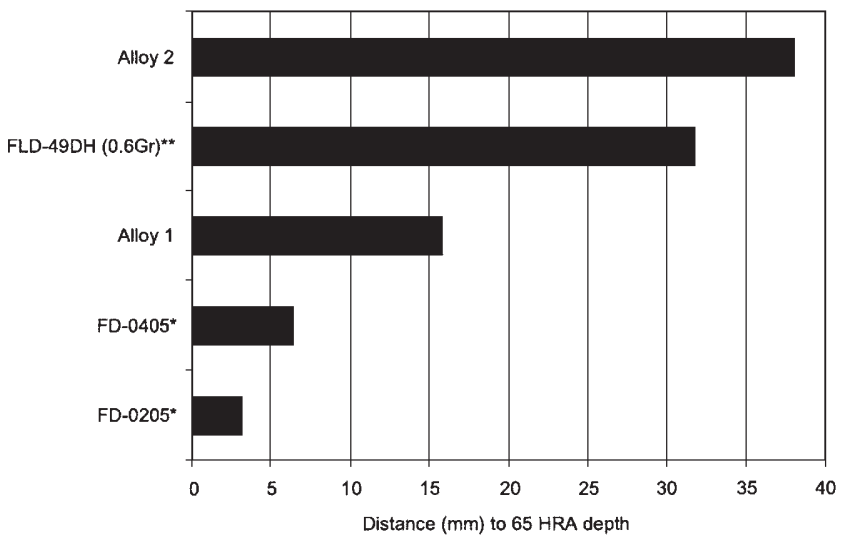

Fig.8 Jominy end-quench hardenability of the 5 alloys studied. *Values for FD-0205 and FD-0405 are taken from MPIF standard $35 ; * * \mathrm{FLD}-49 \mathrm{DH}$ austenitized at $950^{\circ} \mathrm{C}$.

found that Alloy 2 has the highest hardenability of the alloys studied, with a depth of $38 \mathrm{~mm}$. Alloy 2 hardenability may be under-reported with an austenitizing temperature of $900{ }^{\circ} \mathrm{C}$, as it was found that the Jominy depth of another hybrid PM alloy based on $0.8 \%$ Mo increased when the austenitizing temperature was increased above $900^{\circ} \mathrm{C}^{9}$. Therefore, the $\mathrm{J}$ depth of Alloy 2 may in fact be greater than $38 \mathrm{~mm}$.

\section{Discussion}

Many PM parts are designed based on a certain apparent hardness and/or yield strength. Yield strength is important as it defines the highest stress prior to permanent deformation. Once a component exceeds the yield point and plastically deforms, tolerances may be lost and the assembly will cease operating as intended. The Mn-containing alloys in the current study achieve the goals of high hardness and high yield strength in a cost-effective manner by combining a moderate amount of prealloyed molybdenum with admixed manganese. While some additive systems require high temperature and/or long sintering times, the Mn rapidly diffuses to develop the desired microstructure. Given the requirement for $\mathrm{N}_{2}-\mathrm{H}_{2}$ atmospheres, it has been shown that the current system exhibits a robust sintering response ${ }^{8)}$. Even with temperatures lower than $1120^{\circ} \mathrm{C}$, properties decrease moderately in a similar fashion to FD-0405. The Mn-containing alloys should not be sintered or heat-treated in endothermic or exothermic atmospheres.

Another consideration in the use of Mn steels is the fatigue response. An earlier study ${ }^{8)}$ on Alloy 1 showed good axial fatigue strength, just below that of FD-0405. Dudrova et $\mathrm{al}^{5)}$ also showed that Mn steels are well behaved in fatigue. Finally, industrial trials to date have shown good microstructural development and sinter-hardening response. No evidence of accelerated die wear due to the additive has been observed.

\section{Conclusions}

The Mn-containing steels based on Mo prealloys described above can be utilized as cost-effective alternatives 
to $\mathrm{Ni}$ and/or $\mathrm{Cu}$-containing diffusion-alloyed materials for many applications. The behavior of these $\mathrm{Ni}$-free alloys is quite similar to that of the higher molybdenum FLD49DH with respect to mechanical properties and dimensional change. Excellent hardness and yield strength can be achieved with accelerated cooling, as these lean alloys sinter-harden with $0.6 \%$ graphite additions. No special sintering practices are required outside of $\mathrm{N}_{2}-\mathrm{H}_{2}$ based atmospheres. The ANCORBOND FLM Mn alloys are good candidates to replace more highly alloyed diffusionbased products in many applications where higher hardness and yield strength are required.

\section{Acknowledgements}

The authors would like to thank Peter Sokolowski for providing the Jominy end-quench data. They would also like to thank Barry Diamond and Jerry Golin for generating the mechanical property data and microstructures found within the manuscript.

\section{References}

1) J. Tengzelius, S-E. Grek, and C-A. Blande: "Limitations and possibilities in the utilization of $\mathrm{Cr}$ and $\mathrm{Mn}$ as alloying elements in high strength sintered steels", Modern Developments in Powder Metallurgy, Edited by H. Hausner, H. Antes, and G. Smith, MPIF, Princeton, NJ, 13(1980) 159.

2) W.B. James and R.J. Causton: "Surface-Hardenable heat treated P/M steels", Advances in Powder Metallurgy \& Particulate Materials, compiled by J. Capus and R. German, MPIF, Princeton, NJ, 5(1992)65.

3) A. Salak: "High-strength sintered manganese steel", Modern Developments in Powder Metallurgy, Edited by H. Hausner, H. Antes, and G. Smith, MPIF, Princeton, NJ, 13(1980) 183.
4) S. Banerjee, G. Schlieper, F. Thummler, and G. Zapf: "New results in the master alloy concept for high strength sintered steels", Modern Developments in Powder Metallurgy, Edited by H. Hausner, H. Antes and G. Smith, MPIF, Princeton, NJ, 13(1980)143.

5) E. Dudrova, M. Kabatova, R. Bidulsky, and A.S. Wronski: "Industrial processing, microstructures and mechanical properties of Fe-(2-4) Mn(-0.85Mo)-(0.30.7)C sintered steels", Powder Metallurgy, 47(2004) 181.

6) Z. Zhang, K. Frisk, A. Salwen, and R. Sandstrom: "Mechanical properties of $\mathrm{Fe}-\mathrm{Mo}-\mathrm{Mn}-\mathrm{Si}$-C sintered steels", Powder Metallurgy, 47(2004)239.

7) S. Sainz, V. Martinez, M. Dougan, F. Baumgaertner, and F. Castro: "Sinterability, hardenability and mechanical properties of Mn-containing PM steels through the use of a specially designed $\mathrm{Fe}-\mathrm{Mn}-\mathrm{C}$ master alloy", Advances in Powder Metallurgy \& Particulate Materials, compiled by W.R. Gasbarre and J.W. von Arx, MPIF, Princeton, NJ, 7(2006)95-108.

8) B. Lindsley: "High performance manganese containing PM steels", Advances in Powder Metallurgy \& Particulate Materials, compiled by R. Lawcock, A. Lawley, and P.J. McGeehan, MPIF, Princeton, NJ, 7 (2008) 17-25.

9) P.K. Sokolowski and B.A. Lindsley: "Influence of chemical composition and austenitizing temperature on hardenability of PM steels", Advances in Powder Metallurgy \& Particulate Materials, compiled by T. J. Jesberger and S. J. Mashl, MPIF, Princeton, NJ, 7(2009) 1-15.

10)W.B. James, B. Lindsley, H.G. Rutz, and K.S. Narasimhan: "Lean hybrid low-alloy PM molybdenum steels", Euro PM2009, EPMA, Shrewsbury, UK, 1 (2009)23-28. 